\title{
Damage index in childhood-onset systemic lupus erythematosus in Egypt
}

Samia Salah ${ }^{1,2}$, Hala M Lotfy ${ }^{1 *}$, Abir N Mokbel ${ }^{2}$, Ahmed M Kaddah ${ }^{1}$ and Nouran Fahmy ${ }^{1}$

\begin{abstract}
Background: To investigate the prevalence of cumulative organ damage among Egyptian children with juvenileonset systemic lupus erythematosus (jSLE) and the relationships between the organ damage and the demographic data, clinical variables, and disease activity.

Methods: A total of 148 patients with jSLE have been followed in the pediatric rheumatology clinic and section at Cairo University. These patients were evaluated by retrospective chart review. The organ system damage due to SLE was measured using the Systemic Lupus International Collaborating Clinics/American College of Rheumatology Damage Index (SDI). Risk factors for damage were also studied including demographic criteria as well as clinical and laboratory manifestations.

Results: Overall, $43.9 \%$ of the patients had damage within a mean of $6.57 \pm 3.59$ years of disease diagnosis. Neuropsychiatric (NPS-21\%) and renal (16.9\%) system involvement were observed most frequently, followed by cardiovascular (11.5\%), skin (9.5\%), pulmonary (6.1\%), and ocular (4.8\%), with a mean SDI score of $0.93 \pm 1.37$. In our study, the presence of neuropsychiatric manifestations at diagnosis showed the strongest association with the presence of later disease damage.

The number of SLE diagnostic criteria at presentation was strongly associated with the total SDI score, and the renal damage was significantly more prevalent in patients with age at disease diagnosis below 10 years of age. A higher mean disease duration was found in patients with musculoskeletal damage.

Conclusion: We found that cumulative organ damage, as measured by the SDI, was present in $43.9 \%$ of Egyptian patients with juvenile-onset SLE. The damage was significantly more likely in patients who had more SLE diagnostic criteria at time of disease presentation and NPS manifestations at the time of diagnosis.
\end{abstract}

Keywords: Organ damage, systemic lupus erythematosus, Egyptian children

\section{Background}

Systemic lupus erythematosus (SLE) is a chronic autoimmune disease characterized by autoantibodies directed against nuclear antigens and causing a variety of clinical and laboratory abnormalities [1]. SLE may involve multiple organs, causing significant morbidity and mortality in adults, adolescents, and children [2].

Over the last few decades, there has been a remarkable improvement of survival among patients with juvenile-onset systemic lupus erythematosus (jSLE). Case series from the 1980s and 1990s document that 83-93\% of patients survive for 5 years [3] with some authors

\footnotetext{
* Correspondence: dr_hlotfy@yahoo.com

${ }^{1}$ Department of Pediatrics Faculty of Medicine, Cairo University

Full list of author information is available at the end of the article
}

reporting $76-85 \%$ of patients alive at 10 years [4]. The improved survival may be due to earlier diagnosis and better approaches to treatment [5]. Other factors such as improved intensive care unit medical care and other supportive services may have a role. As a result, children and adolescents with jSLE are now faced with considerable morbidity due to the sequelae of disease activity, side effects of medications, and comorbid conditions [6]. This morbidity may affect their long-term quality of life, leading to problems related to the physical and psychological adaptation to a chronic severe illness. The management of patients with jSLE is now directed not only at preventing death, but also at lessening the development of permanent damage to involved organ systems
C Biomed Central

(C) 2011 Salah et al; licensee BioMed Central Ltd. This is an Open Access article distributed under the terms of the Creative Commons Attribution License (http://creativecommons.org/licenses/by/2.0), which permits unrestricted use, distribution, and reproduction in any medium, provided the original work is properly cited. 
resulting from the disease, its therapy, or disease complications [6].

The Systemic Lupus International Collaborating Clinics/American College of Rheumatology Damage Index (SDI) [7] is an instrument that includes assessment of 12 body organ systems and helps document irreversible damage occurring in patients with lupus. The objective of the present study is to investigate the frequency of accumulated organ damage in Egyptian patients with jSLE and to assess its association with demographic, clinical factors, and disease activity.

\section{Methods}

The present study included 148 Egyptian patients with jSLE all fulfilling the inclusion criteria of this work, which were as follows: (1) Each patient having four or more of the 1997 revised American Rheumatism Association SLE criteria at the time of assessment of damage [8]; (2) Each patient age at disease diagnosis at or below 16 years; and (3) All patients having a disease duration of 6 months at study entry.

All patients were recruited from, and were followed up at, the Pediatric Rheumatology clinic of Cairo University Children's Hospital in Cairo, Egypt from January 1990 to December 2008. Initial data at the time of first presentation were obtained for all patients using chart review. The follow-up data extracted from the files were used to confirm the presence of damage at that point of damage assessment. Patients who died were excluded as well as loss-to-follow-up patients who failed to attend the clinic for more than 12 months. Patients whose follow-up was less than one year were also excluded from the study.

For all patients, demographic and clinical information were reviewed including: 1) Sex; 2) Age of disease diagnosis; 3) Age at time of assessment; 4) Disease duration from diagnosis to study visit; 5) Disease manifestations at presentation; and 5) Clinical and laboratory data that might represent risk factors for the development of permanent damage.

The time of disease presentation was defined as the time of development of the first ACR SLE criterion. Lupus activity was assessed by the SLE Disease Activity Index (SLEDAI) [9]. The accumulated damage was measured by the SDI [7]. Briefly, the SDI is a validated physician-rated instrument consisting of 41 items in 12 organ systems/domains ascertained by clinical assessment and has a possible range of 0-49. Damage is defined as any nonreversible change, not related to active inflammation, occurring since onset of SLE, detected by clinical assessment, and present for at least 6 months. Damage may be due to the disease itself, its treatment, or comorbid conditions [7]. As growth failure represents a significant source of damage in the pediatric age that is not included in the SDI, we also recorded its occurrence. Growth failure was defined as a height below the 5 th percentile for age or a decreased growth that crossed 2 major percentiles [10]. Growth assessment was based on Egyptian growth curves [11]. Assessment of delayed puberty was also important for evaluation of damage in patients with jSLE. Delayed puberty was defined as delay in development of secondary sexual characteristics of more than 2SD below the mean for age by Tanner staging $[10,12]$. All medications utilized were also recorded.

Statistical analysis was done using the statistical package for social science (SPSS), version 14. Nominal data were expressed as frequency and percentage and were compared using the chi square test. Numerical data were expressed as range, mean and standard deviation and were compared using $\mathrm{t}$ tests. $\mathrm{P}$ values less than 0.05 were considered significant.

Ethics approval from the Research Ethics Committee, Faculty of Medicine, Cairo University, was not necessary according to University and Research Ethics Committee guidelines as all data and laboratory tests were obtained from patients' records, and as a part of their routine follow-up. All patient data was kept confidential.

\section{Results and discussion}

The study included 148 patients; 103 females (69.6\%) and 45 males $(30.4 \%)$. The female to male ratio was 2.3:1. The mean age of diagnosis of jSLE was $10.5 \pm$ 2.75 years (range 2-16 years). The mean disease duration was $6.57 \pm 3.59$ years.

The mean age at study visit was $17.1 \pm 3.8$ years. At presentation, constitutional manifestations were present in $(44.6 \%)$, followed by mucocutaneous $(27.7 \%)$, arthritis (27.7\%), renal (21.6\%), hematologic (10.8\%), and NSP problems (10.1\%).

The clinical and laboratory characteristics of these patients throughout the disease course were summarized in Table 1. The number of diagnostic criteria present in patients at disease presentation are summarized in Table 2.

Disease activity and cumulative organ damage in the patients were assessed simultaneously at the study visit, as shown in Table 3. Overall, $43.9 \%$ patients had damage, with at least one item in the SDI (SDI 1), with a mean time of $6.57 \pm 3.59$ years from disease onset to the time of assessment. The mean SDI score was $0.93 \pm$ 1.37 (range 0 - 6). The frequency of damage by organ system is shown in Table 4 with comparative results of 2 other similar studies. The organ systems most frequently affected by damage were the NSP (21\%), renal (16.9\%), cardiovascular (11.5\%), skin $(9.5 \%)$, ocular (6.1\%), pulmonary $(6.1 \%)$ and musculoskeletal (3.4\%) systems. Only 2 patients (1.4\%) developed diabetes and 
Table 1 Clinical and laboratory characteristics of 148 patients with juvenile-onset systemic lupus erythematosus

\begin{tabular}{lc}
\hline Manifestation & (N.)percentage \\
\hline Constitutional & $(85) 58.1 \%$ \\
\hline Mucocutaneous & $(113) 76.4 \%$ \\
\hline Musculoskeletal & $(77) 52.7 \%$ \\
\hline Hematological & $(81) 55.4 \%$ \\
\hline Renal & $(96) 65.5 \%$ \\
\hline Neuropsychiatric & $(20) 31.8 \%$ \\
\hline Gastrointestinal & $(11) 8.1 \%$ \\
\hline Cardiovascular & $(59) 39.9 \%$ \\
\hline Pulmonary & (31) $21.6 \%$ \\
\hline Hemoratory features & $(40) 27.6 \%$ \\
\hline Leucopenia & (54) $36.8 \%$ \\
\hline Thrombocytopenia & $(45) 30.9 \%$ \\
\hline ANA & (139) $94.1 \%$ \\
\hline Anti-ds DNA & (65) $44.1 \%$ \\
\hline
\end{tabular}

N.: number

no malignancies were reported. The frequency of growth failure was $28.3 \%$, while delayed puberty was present in $15.1 \%$ of our patients.

The distribution of patients according to SDI score is shown in Figure 1. The summary of drug therapies utilized by the patients throughout the disease course is reported in Table 5. Statistical analyses were conducted by comparing variables in patients classified according to the presence or absence of damage (i.e., patients with SDI $\geq 1$ versus patients with $\mathrm{SDI}=0$ ).

There was a significant correlation between the damage index and the total number of diagnostic criteria at presentation ( $\mathrm{p}$ value $=.007$ and $\mathrm{r}=.236$ ). Thus, an increased number of diagnostic criteria at presentation may increase the chance of developing more organ damage over time.

The presence of damage was also associated with the presence of the NPS ACR criterion (neuropsychiatric

Table 2 the number of diagnostic criteria present in 148 patients at time of presentation

\begin{tabular}{ll}
\hline Number of criteria at diagnosis & Percent of patients \\
\hline 2 & $5.4 \%$ \\
\hline 3 & $16.9 \%$ \\
\hline 4 & $37.7 \%$ \\
\hline 6 & $20.8 \%$ \\
\hline 7 & $13.8 \%$ \\
\hline 8 & $4.6 \%$ \\
\hline
\end{tabular}

All patients were assessed
Table 3 Results of disease activity and organ damage assessments

\begin{tabular}{lcc}
\hline SLEDAI & 12.88 & \pm 7.31 \\
\hline SDI & 0.93 & \pm 1.37 \\
\hline
\end{tabular}

SLEDAI = Systemic Lupus Erythematosus Disease Activity Index (score range 0105); SDI = Systemic Lupus International Collaborating Clinics/American College of Rheumatology Damage Index (score range 0-49).

manifestations by American College of Rheumatology SLE criteria) at the time of SLE diagnosis ( $\mathrm{p}=.018)$, i.e. patients with the NPS will have an increased chance of developing damage. Linear regression analysis was done for predictors of damage as detected by univariate analysis, again showing significance with the number of diagnostic criteria at presentation $(\mathrm{p}=0.042)$ and NPS damage $(\mathrm{p}=0.014)$.

We found that the renal damage was more prevalent in the group below 10 years of age at onset compared to children who presented at age greater than 10 years of age $(\mathrm{p}=.002)$. The mean disease duration of patients with musculoskeletal damage as assessed by the musculoskeletal (MSK) damage item in the SDI was significantly higher than in those without MSK damage $(p=.0450)$. Thus it appeared that in our jSLE patients, the longer the jSLE disease duration, the more likely musculoskeletal damage will occur. The correlations between the SDI and drug therapies were not assessed as the total dose of each medication, as well as the duration of use, could not be assessed precisely for all patients. No association was found between disease activity assessed by SLEDAI and jSLE organ damage at the study visit.

Systemic lupus erythematosus is an autoimmune disease in which children and adolescents represent 15$20 \%$ of all patients [13]. Several studies have reported a wide range of variation in the natural history of jSLE among different ethnic and geographical groups [14], including studies among Egyptian children [15].

As a result of marked improvement in the prognosis of jSLE [5] with decreased mortality, more attention is now paid to morbidity as an indicator of outcome, as measured in terms of organ dysfunction resulting from the disease and its treatment $[16,17]$

In this work we studied the cumulative organ damage, as measured by the SDI, in 148 patients with jSLE with a mean disease duration of $6.57 \pm 3.59$ years.

Demographic, clinical and laboratory features of our patients are comparable to the jSLE features that have been reported in many other studies conducted in jSLE patients $[6,18]$ and to studies among Egyptian children $[15,19]$

Significant cumulative damage, with at least one item in the SDI ( $S D \geq 1)$, was present in $43.9 \%$ of our children, with the mean SDI score of $0.93 \pm 1.37$ (range 0 - 
Table 4 Frequency of damage in the 12 organ systems/domains and the 41 items of the SDI, in our study group, with comparison with the 2 other cohorts

\begin{tabular}{|c|c|c|c|}
\hline Item & $\begin{array}{c}\text { Percentage } \\
\text { For our Egyptian } \\
\text { study group } 2012\end{array}$ & $\begin{array}{l}\text { Percentage } \\
\text { For Brunner HI et al, pediatric } \\
\text { study group } 2008 \text { [24] }\end{array}$ & $\begin{array}{l}\text { Percentage for Gutiérrez etal, } \\
\text { study group } 2006[20]\end{array}$ \\
\hline Ocular & $6.1 \%$ & $42.4 \%$ & $8.2 \%$ \\
\hline Cataract & $3.4 \%$ & 42.4 & \\
\hline Retinal change or optic atrophy & $2.7 \%$ & & \\
\hline Neuropsychiatric & $21 \%$ & $12.1 \%$ & $10.7 \%$ \\
\hline Cognitive impairment or major psychosis & $8.8 \%$ & & \\
\hline Seizures requiring therapy for 6 months & $9.5 \%$ & & \\
\hline Cerebrovascular accident & $2.7 \%$ & & \\
\hline $\begin{array}{l}\text { Cranial or peripheral neuropathy (excluding } \\
\text { optic) }\end{array}$ & $0 \%$ & & \\
\hline Transverse myelitis & $0 \%$ & & \\
\hline Renal & $16.9 \%$ & $9.1 \%$ & $13 \%$ \\
\hline $\begin{array}{l}\text { Estimated or measured glomerular filtration } \\
\text { rate }<50 \%\end{array}$ & $5.4 \%$ & & \\
\hline Proteinuria $\geq 3.5 \mathrm{gm} / 24$ hours & $6.1 \%$ & & \\
\hline End-stage renal disease & $5.4 \%$ & & \\
\hline Pulmonary & $6.1 \%$ & $3 \%$ & $1.8 \%$ \\
\hline Pulmonary hypertension & $4.7 \%$ & & \\
\hline Pulmonary fibrosis & $1.4 \%$ & & \\
\hline Shrinking lung & $0 \%$ & & \\
\hline Pleural fibrosis & $0 \%$ & & \\
\hline $\begin{array}{l}\text { Pulmonary infarction or lung resection not } \\
\text { for malignancy }\end{array}$ & $0 \%$ & & \\
\hline Cardiovascular & $11.5 \%$ & $1.5 \%$ & $3 \%$ \\
\hline Angina or coronary artery bypass & $0 \%$ & & \\
\hline Myocardial infarction & $0 \%$ & & \\
\hline Cardiomyopathy & $2 \%$ & & \\
\hline Valvular disease & $7.4 \%$ & & \\
\hline Pericarditis for 6 months or pericardiectomy & $3.4 \%$ & & \\
\hline Peripheral vascular & $(4.8 \%)$ & $3 \%$ & $4.8 \%$ \\
\hline Claudication for 6 months & $0 \%$ & & \\
\hline Minor tissue loss & $1.4 \%$ & & \\
\hline Significant tissue loss & $1.4 \%$ & & \\
\hline $\begin{array}{l}\text { Venous thrombosis with swelling ulceration } \\
\text { or venous stasis }\end{array}$ & $2 \%$ & & \\
\hline Gastrointestinal & $0.7 \%$ & $3 \%$ & $2.2 \%$ \\
\hline $\begin{array}{l}\text { Infarction or resection of bowel, spleen, liver, } \\
\text { or gall bladder }\end{array}$ & $0.7 \%$ & & \\
\hline Mesenteric insufficiency & $0 \%$ & & \\
\hline Chronic peritonitis & $0.7 \%$ & & \\
\hline $\begin{array}{l}\text { Stricture or upper gastrointestinal tract } \\
\text { surgery }\end{array}$ & $0 \%$ & & \\
\hline $\begin{array}{l}\text { Pancreatic insufficiency requiring enzyme } \\
\text { replacement or with pseudo cyst }\end{array}$ & $0 \%$ & & \\
\hline Musculoskeletal & $3.4 \%$ & $16 \%$ & $10.7 \%$ \\
\hline Muscle atrophy or weakness & $0 \%$ & & \\
\hline Deforming or erosive arthritis & $0 \%$ & & \\
\hline
\end{tabular}


Table 4 Frequency of damage in the 12 organ systems/domains and the 41 items of the SDI, in our study group, with comparison with the 2 other cohorts (Continued)

\begin{tabular}{|c|c|c|c|}
\hline $\begin{array}{l}\text { Osteoporosis with fracture or vertebral } \\
\text { collapse }\end{array}$ & $1.4 \%$ & & \\
\hline Avascular necrosis & $1.4 \%$ & & \\
\hline Osteomyelitis & $0.7 \%$ & & \\
\hline Ruptured tendons & $0 \%$ & & \\
\hline Skin & $9.5 \%$ & $5 \%$ & $6.7 \%$ \\
\hline Scarring chronic alopecia & $6.1 \%$ & & \\
\hline $\begin{array}{l}\text { Extensive scarring or panniculum other than } \\
\text { scalp and pulp space }\end{array}$ & $1.4 \%$ & & \\
\hline $\begin{array}{l}\text { Skin ulceration (excluding thrombosis) for } \\
\text { more than } 6 \text { months }\end{array}$ & $2 \%$ & & \\
\hline Premature gonadal failure & $0 \%$ & & $2.9 \%$ \\
\hline Diabetes & $1.4 \%$ & $3 \%$ & $0.4 \%$ \\
\hline Malignancy & $0 \%$ & $0 \%$ & $0 \%$ \\
\hline Growth failure & $28.3 \%$ & & $15.3 \%$ \\
\hline Delayed puberty & $15.1 \%$ & & $11.3 \%$ \\
\hline
\end{tabular}

SDI = Systemic Lupus International Collaborating Clinics/American College of Rheumatology Damage Index N.B: One patient may have more than one damage criteria

6). This is considerably lower than the damage in some other pediatric series which ranged from $61 \%$, to $50.5 \%$ $[6,20]$, but more than the percentage of damage reported in the study of Gutiérrez-Suárez et al., in which damage was detected in $39.9 \%$ of patients [21].
However, this difference in our study group may be due to an earlier age of disease diagnosis (mean $10.5 \pm 2.75$ years) and longer disease duration (mean $6.57 \pm 3.593$ years), when compared to those in the study of Gutiérrez-Suárez et al.

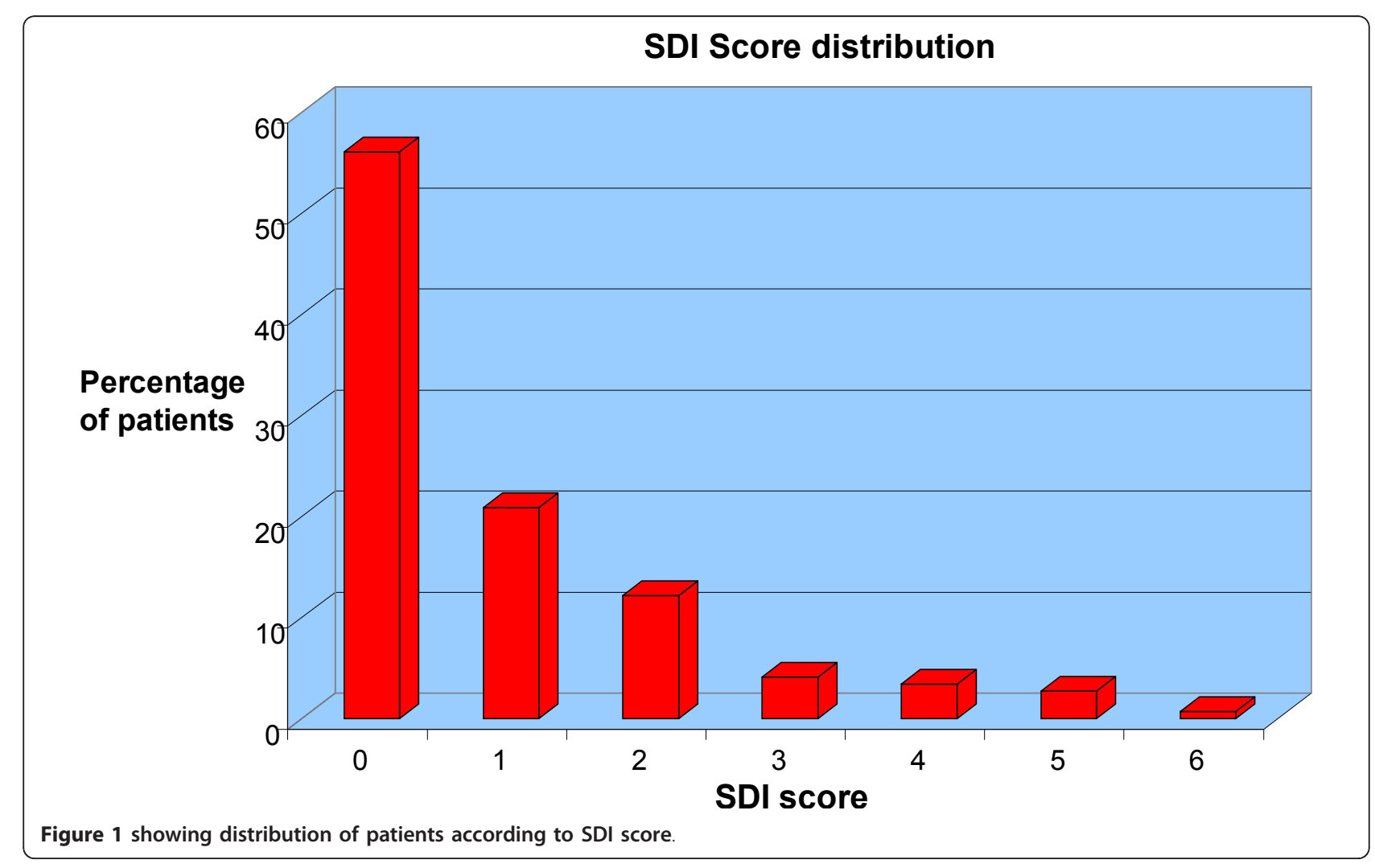




\begin{tabular}{rrr}
\hline & Medication & \% of patients who received the therapy \\
\hline Antimalarial medications, either daily or 3 times weekly & $\mathbf{8 3 . 0 \%}$ \\
\hline Oral prednisone, either daily or alternate day & $\mathbf{9 7 . 8 \%}$ \\
\hline Cyclophosphamide pulses $\left(500-1000 \mathrm{mg} / \mathrm{m}^{2}\right)$ & $\mathbf{6 7 . 7 \%}$ \\
\hline Azathioprine & $\mathbf{4 2 \%}$ \\
\hline Mycofenolate mofetil & $\mathbf{4 5 \%}$ \\
\hline Cyclosporine & $\mathbf{8 \%}$ \\
$\mathbf{3} \%$ \\
\hline
\end{tabular}

In our series, neuropsychiatric (NPS) damage was the most frequent type of damage, occurring in $21 \%$ of our patients. This is less than the percentage of neuropsychiatric damage reported by Lilleby et al. (28\%) [20]. On the other hand, neuropsychiatric damage was higher than many other series. In these other studies the neuropsychiatric damage ranged from $15.8 \%$ [5] to $10.7 \%$ [21]. The higher percentage of neuropsychiatric damage in our series is mainly in the form of seizures, persisting more than 6 months, or cognitive impairment. Cognitive impairment was assessed in our patients only on a clinical basis, without using specific neurocognitive testing, and without any comparisons with previous cognitive assessments done to these patients.

Whether this clinical assessment without testing affects the results or not is unclear. In our study, renal damage was the second most common type of damage, occurring in $16.9 \%$ of the children. This high percentage of renal damage may be due to a high percentage of renal involvement in juvenile SLE in Egyptian children with renal disease as high as $65.5 \%$, with relatively high percentage of Class III and Class IV nephritis, occurring in $25 \%$ and $22.5 \%$ of children and adolescents with jSLE, respectively [19].

Renal damage in our study was slightly less than that reported by some series (21.8\%) [5] and higher than those in other series $[20,21]$ where renal damage was detected in only $13 \%$ of patients.

Moreover, cardiovascular damage occurred in $11.5 \%$ of our children, of which $7.4 \%$ were due to valvular disease, as detected by the presence of diastolic or systolic murmur of a minimum grade of $3 / 6$. However, due to the high prevalence of rheumatic fever heart disease in Egypt [22], further investigations regarding the possibility that some of these murmurs may be due to previously undiagnosed rheumatic fever carditis may be prudent. Skin damage was detected in $9.5 \%$ of our patients, with a scarring chronic alopecia being the commonest manifestation in $6.1 \%$. This result is consistent with the study of Ravelli et al. 2005 (9.6\%), but higher than that reported by Gutiérrez-Suárez et al. (7.6\%) [21].
Although all investigators agreed that the estimation of SDI was appropriate for patients with jSLE, assessment of growth and pubertal age were also conducted for better assessment of jSLE damage for children and adolescents. The frequency of growth failure in our study group, was $28.3 \%$, which is much higher than that reported by Gutiérrez-Suárez et al.(15.1\%) [21]. This high rate of growth failure may be partly related to prolonged corticosteroid use and partly due to poor nutritional status of some of our children of low socioeconomic background. Disease activity may also play a role.

Delayed puberty was detected in $15.1 \%$ of our patients when assessed at time of assessment of damage. This percentage of puberty delay is slightly higher than the results of Gutiérrez-Suárez et al. (11.3\%) [[20]]. This delayed puberty is a very important form of damage affecting the adolescent growth spurt of patients and sexual development and often leads to emotional and social difficulties.

When compared to adult series, the mean SDI score and the frequency of cumulative damage recorded in our patients were in the low range, with the mean SDI score being $1.51 \pm 1.97$ and the frequency of damage being $60 \%$. For example, the higher percentage of damage in an adult series were obvious with frequencies such as musculoskeletal damage in $22 \%$, ocular damage in $13 \%$, and diabetes mellitus reported in $6 \%$ of adult patients [1]. This higher rate of damage in adults may be related to cumulative and high dose prednisone or the presence of other risk factors as smoking, obesity and atherosclerosis [1]. Renal damage was more prevalent in patients with younger disease presentation and with longer disease duration, which agrees with other pediatric and adult series [23,24].

No association was found between SLEDAI and SDI, which is expected as SDI describes accumulated damage over a period of time, whereas, SLEDAI is as assessment of disease activity at a certain time. The best way to assess the burden of the ongoing jSLE disease activity may be by assessing SLEDAI scores over time and by the area under the ROC curve. We acknowledge that one of the limitations of this work is our assessment of 
disease activity by the SLEDAI at one point of time only and that approach prevents such burden assessment.

The presence of damage was more prevalent in patients having a higher number of diagnostic criteria at disease presentation, as well as in those with neuropsychiatric manifestations at presentation, which is in concordance with other pediatric series [6].

Therefore, in these patients, proper management and follow-up are of great importance due to higher risk of development of permanent organ damage [6].

Assessment of the cumulative drug doses in our patients and its correlation with damage was not possible due to the large number of patients and lack of accurate recordings for all patients, especially with children with long disease durations. This is a significant limitation of our study as we could not correlate treatment with organ damage as done by Lilleby et al [20].

\section{Conclusions}

The evidence of cumulative organ damage, as measured by the SDI, was found in $43.9 \%$ of our jSLE patients, and was not related to disease activity assessed by SLEDAI. Damage was significantly more likely in patients with longer disease duration and NPS manifestations at the time of diagnosis. These high risk groups require a strict management plan and follow-up. Growth retardation and delayed puberty are important items of jSLE damage that should be assessed in children, and attention should be paid to their prevention.

Acknowledgements
Special thanks to all Rheumatology Clinic members, who helped us in our
work, and to our dear patients, who participated in conducting the study.

\section{Author details}

${ }^{1}$ Department of Pediatrics Faculty of Medicine, Cairo University. ${ }^{2}$ Department of Rheumatology Faculty of Medicine, Cairo University.

\section{Authors' contributions}

SS: head of the pediatric rheumatology department Cairo University; participated in study conceptualization, supervision of the work steps, and critical revision of the manuscript. HL participated in data collection, statistical analysis of the results, writing the manuscript, and publication correspondence. AN participated in study conceptualization, data collection, interpretation of the results and final approval of the manuscript. AMK participated in statistical analysis of the results, helped in writing the manuscript and supervision of the work steps. NF shared in data collection, tabulation of data, and final approval of the Manuscript. All authors read and approved the final manuscript.

\section{Competing interests}

The authors declare that they have no competing interests.

Received: 11 August 2011 Accepted: 9 December 2011 Published: 9 December 2011

\section{References}

1. Zonana-Nacach A, Barr SG, Magder LS, Petri M: Damage in systemic lupus erythematosus and its association with corticosteroids. Arthritis Rheum 2000, 43:1801-1808.
2. Perfumo F, Martini A: Lupus nephritis in children. Lupus 2005, 14:83-88.

3. Tucker LB, Menon S, Schaller JG, Isenberg DA: Adult and childhood-onset systemic lupus erythematosus: A comparison of onset, clinical features, serology, and outcome. Br J Rheumatol 1995, 34:866-72.

4. Platt JL, Burke BA, Fish AJ, Kim Y, Michael AF: Systemic lupus erythematosus in the first two decades of life. Am J Kidney Dis 1982 2:212-22.

5. Ravelli A, Ruperto N, Martini A: Outcome in juvenile onset systemic lupus erythematosus. Curr Opin Rheumatol 2005, 17:568-73.

6. Ravelli A, Duarte-Salazar C, Buratti S, Reiff A, Bernstein B, MaldonadoVelazquez MR, Beristain-Manterola R, Maeno N, Takei S, Gerloni V, Spencer CH, Pratsidou-Gertsi P, Ruperto N, Pistorio A, Martini A: Assessment of damage in juvenile-onset systemic lupus erythematosus: $A$ multicenter cohort study. Arthritis Rheum 2003, 49:501-7.

7. Gladman D, Ginzler E, Goldsmith C, Fortin P, Liang M, Urowitz M, Bacon P, Bombardieri S, Hanly J, Hay E, Isenberg D, Jones J, Kalunian K, Maddison P, Nived O, Petri M, Richter M, Sanchez-Guerrero J, Snaith M, Sturfelt G, Symmons D, Zoma A: The development and initial validation of the Systemic Lupus International Collaborating Clinics/American College of Rheumatology damage index for systemic lupus erythematosus. Arthritis Rheum 1996, 39:363-9.

8. Petri M: Review of classification criteria for systemic lupus erythematosus. Rheum Dis Clin North Am 2005, 31:245-254.

9. Bombardier C, Gladman DD, Urowitz MB, Caron D, Chang CH: Derivation of the SLEDAl: A disease activity index for lupus patients. The Committee on Prognosis Studies in SLE. Arthritis Rheum 1992, 35:630-40.

10. Tanner JM, Davies PS: Clinical longitudinal standards for height and height velocity for North American children. J Pediatr 1985, 107:317-29.

11. Egyptian Growth Curves: Diabetes Endocrine Metabolism Pediatric Unit Cairo University Childern's Hospital., http://dempuegypt.blogspot.com/. Revised 29-11- 2008. Accessed 5-12-2010.

12. Pozo J, Argente J: Delayed puberty in chronic illness. Best Pract Res Clin Endocrinol Metab. 2002, 16:73-90.

13. Stichweh D, Arce E, Pascual V: Update on pediatric systemic lupus erythematosus. Curr Opin Rheumatol 2004, 16:577-87.

14. Alarcón GS, Friedman AW, Straaton KV, Moulds JM, Lisse J, Bastian HM, McGwin G Jr, Bartolucci AA, Roseman JM, Reveille JD: Systemic lupus erythematosus in three ethnic groups: III A comparison of characteristics early in the natural history of the LUMIN cohort. Lupus 1999, 8:197-209.

15. Salah S, Lotfy HM, Sabry SM, El Hamshary A, Taher H: Systemic lupus erythematosus in Egyptian children. Rheumatol Int 2009, 29:1463-8, PMID: 19301009.

16. Ruperto N, Buratti S, Duarte-Salazar C, Pistorio A, Reiff A, Bernstein B, Maldonado-Velázquez MR, Beristain-Manterola R, Maeno N, Takei S, Falcini F, Lepore L, Spencer CH, Pratsidou-Gertsi P, Martini A, Ravelli A: Health-related quality of life in juvenile-onset systemic lupus erythematosus and its relationship to disease activity and damage. ArthritisRheum 2004, 51:458-64

17. Lacks S, White P: Morbidity associated with childhood systemic lupus erythematosus. J Rheumatol 1990, 17:941-5.

18. Carreño L, López-Longo FJ, Monteagudo I, Rodríguez-Mahou M, Bascones M, González CM, Saint-Cyr C, Lapointe N: Immunological and clinical differences between juvenile and adult onset of systemic lupus erythematosus. Lupus 1999, 8:287-92.

19. Mahmoud SS, Bazaraa HM, Lotfy HM, Abd-El-Aziz DM: Renal involvement in childhood-onset systemic lupus erythematosus in Egypt. Rheumatol Int.

20. Lilleby $V$, Flatø B, Førre O: Disease duration, hypertension and medication requirements are associated with organ damage in childhood-onset systemic lupus erythematosus. Clin Exp Rheumatol 2005, 23:261-9.

21. Gutiérrez-Suárez R, Ruperto N, Gastaldi R, Pistorio A, Felici E, BurgosVargas R, Martini A, Ravelli A: A proposal for a pediatric version of the Systemic Lupus International Collaborating Clinics/American College of Rheumatology Damage Index based on the analysis of 1,015 patients with juvenile-onset systemic lupus erythematosus. Arthritis Rheum 2006, 54:2989-96, PMID: 16947634.

22. Abdel-Moula AM, Sherif AA, Sallam SA, Mandil AM, Kassem AS, Zaher SR: Prevalence of rheumatic heart disease among school children in Alexandria, Egypt: a prospective epidemiological study. J Egypt Public Health Assoc 1998, 73:233-54.

23. Freire EA, Maia IO, Nepomuceno JC, Ciconelli RM: Damage index assessment and quality of life in systemic lupus erythematosus patients 
with long term disease in Northeastern Brazil. Clin Rheumatol 2007,

26:423-8.

24. Brunner HI, Gladman DD, Ibañez D, Urowitz MD, Silverman ED: Difference in disease features between childhood-onset and adult-onset systemic lupus erythematosus. Arthritis Rheum 2008, 58:556-62.

doi:10.1186/1546-0096-9-36

Cite this article as: Salah et al.: Damage index in childhood-onset systemic lupus erythematosus in Egypt. Pediatric Rheumatology 2011 9:36.

Submit your next manuscript to BioMed Central and take full advantage of:

- Convenient online submission

- Thorough peer review

- No space constraints or color figure charges

- Immediate publication on acceptance

- Inclusion in PubMed, CAS, Scopus and Google Scholar

- Research which is freely available for redistribution

Submit your manuscript at www.biomedcentral.com/submit
() Biomed Central 